\title{
Storage and lyophilization effects of extracts of Cynara cardunculus on the degradation of ovine and caprine caseins
}

\author{
Freni K. Tavaria, M. José Sousa, F. Xavier Malcata* \\ Escola Superior de Biotecnologia, Universidade Católica Portuguesa, Rua Dr. António Bernardino de Almeida, P-4200-072 Porto, Portugal
}

Keywords: Plant rennet; Lyophilization; Proteolysis; Cheese

\begin{abstract}
Clotting and proteolytic activities are important parameters when evaluating rennets for cheesemaking. Both these activities were determined for extracts of the plant Cynara cardunculus in fresh form and after lyophilization followed by reconstitution, either in water or in citrate buffer ( $\mathrm{pH}$ 5.4) and stored for up to 4 weeks at $4{ }^{\circ} \mathrm{C}$. The patterns of degradation of ovine and caprine caseins were followed by urea polyacrylamide gel electrophoresis in attempts to qualitatively differentiate the activity of the enzyme extracts as storage time elapsed. Storage at $4^{\circ} \mathrm{C}$ significantly decreased the clotting power of the extracts but lyophilization retarded this decrease; $\beta$ - and $\alpha_{\mathrm{s}}$-casein breakdown generally increased with storage time, via patterns that depend on caseinate type and extract used, but lyophilized extracts reconstituted in citrate buffer were significantly less proteolytic than the other extracts. Therefore, it is suggested that lyophilized extracts (reconstituted with citrate buffer) of flowers of $C$. cardunculus be used rather than fresh extracts. (C) 2000 Elsevier Science Ltd. All rights reserved.
\end{abstract}

\section{Introduction}

Enzyme crude extracts from the abomasa of milk-fed calves have provided the first (and best) rennet for general cheesemaking. However, increasing costs and shortage of supply in recent years have encouraged a search for new rennet sources (Green, 1972). Microbial rennets produced by genetically-engineered bacteria and moulds have proven appropriate substitutes for animal rennets, but attention has simultaneously been directed towards proteases extracted from such plants as Ananas comosus (Cattaneo, Nigro, Messina \& Giangiacomo, 1994), Calotropis porcera (Ibiama \& Griffiths, 1987), Benincasa cerifera (Gupta \& Eskin, 1977), Carica papaya (Cabezas, Esteban \& Marcos, 1981), Centaurea calcitrapa (Domingos et al., 1996), Withania coagulans (Singh, Chandler, Bhalerao \& Dastur, 1973) and Dieffenbachia maculata (Padmanabhan, Chitre \& Shastri, 1993), among others.

* Corresponding author. Tel.: + 351-225580004; fax: + 351-225090351 .

E-mail address: xmalcata@esb.ucp.pt (F.X. Malcata).
Notable are the proteases extracted from flowers of the wild thistle (i.e. Cynara spp.) which, although used for years in the manufacture of cheeses from goat's and ewe's milk (Macedo, Malcata \& Oliveira, 1993) in several rural areas of Portugal and Spain, have only recently been isolated, purified and partially characterized (Faro, 1991). Three different species of Cynara have been claimed to be effective rennets: $C$. cardunculus (the most abundant), C. humilis and C. scolymus. Vieira de Sá and Barbosa (1972) were the first to undertake consistent studies encompassing the physicochemical characteristics and technological uses of $C$. cardunculus as a substitute for animal rennet in cheesemaking; its crude aqueous extract exhibited lower clotting activity but higher general proteolytic activity than commercial animal rennets. Heimgartner, Pietrzak, Geertsen, Brodelius, Silva Figueiredo and Pais (1990) and Faro (1991) reported the existence of three different aspartic proteases (tentatively termed cynarases 1,2 and 3), each composed of one large and one small subunit; such proteases are glycoproteins containing $\mathrm{N}$-linked mannose residues and displaying maximum activity at $\mathrm{pH}$ 5.1. Campos, Guerra, Aguiar, Ventura and Camacho (1990) and Cordeiro, Jakob, Pahan, Pais and Brodelius 
(1992) claimed that cynarase 3 exhibits similar clotting activity to, but higher proteolytic activity than chymosin. In addition, the proteolytic activity of cynarases appears to be less specific than that of chymosin: these enzymes are able to hydrolyze $\alpha_{\mathrm{s} 1}$-casein, $\beta$-casein and at least one of the $\gamma$-caseins, have a higher affinity towards $\kappa$-casein (lower $K_{\mathrm{m}}$ ) when compared to other milk-clotting enzymes (Macedo et al., 1993), and display a high specific clotting activity, which makes them suitable for manufacture of soft-bodied cheeses (which are often associated with slightly bitter tastes and relatively low yields).

The urea-PAGE method has been commonly employed to monitor casein breakdown throughout the hydrolysis time frame. Two groups of protein bands can easily be detected; the group with lower mobility contains $\beta$-casein and is divided into two components, $\beta_{1}$ and $\beta_{2}$-casein, which differ in their level of phosphorylation (Richardson \& Creamer, 1976); the group with higher mobility in the ovine casein region consists of three bands (tentatively termed ovine $\alpha_{\mathrm{s}^{-}}, \alpha_{\mathrm{s} 2^{-}}$and $\alpha_{\mathrm{s} 3^{-}}$ caseins), with mobilities similar to those of bovine $\alpha_{\mathrm{s} 3^{-}}$ and $\alpha_{\mathrm{s} 4}$-caseins (Richardson \& Creamer, 1975); the caprine casein comprises two components (tentatively termed $\alpha_{\mathrm{s} 1^{-}}$and $\alpha_{\mathrm{s} 2}$-caseins), where the $\alpha_{\mathrm{s} 1}$-casein group usually contains between three and five peptides (Boulanger, Grosclaude \& Mahé, 1987) and moves faster (Carretero, Trujillo, Mor-Mur, Plas \& Guamis, 1994).

Application of enzymes in biotechnological processes is frequently limited by their rates of deactivation, which can be described as a set of physicochemical phenomena usually associated with denaturation of the native protein molecule as a result of modifications of the secondary, tertiary and/or quaternary structures. Several environmental factors do catalytically promote such detrimental changes in the enzyme structure, e.g. $\mathrm{pH}$, temperature and physico-chemical nature of the reaction medium. However, the information available in the literature regarding the effect of storage on the activity of rennets is scarce; an exception to this rule was provided by El-Salam, El-Dein, Mahfouz, Sharaf and Hefnawy (1989), who reported that rennet activity generally increased during storage up to a maximum at ca. 3 weeks.

The objective of the present work was to determine the effect of storage of extracts of $C$. cardunculus, in native and lyophilized forms, upon their clotting and proteolytic activities. The impetus for this work arose from the virtually empirical storage of this crude rennet, which is certainly one of the major factors that account for a high variability of the final cheese product (such variability actually restricts trade to foreign countries). On the other hand, if the cheeses obtained via coagulation with this plant rennet are to maintain their high added value, associated with unique taste and aroma, then they should be produced with standardized rennets that can support consistent and reproducible results. It is expected that this research effort will contribute towards the aforementioned rennet standardization, via assessment of the variation in catalytic performance brought about by alternative types of storage.

\section{Materials and methods}

\subsection{Enzyme source}

Dried flowers of Cynara cardunculus L., previously collected at similar maturation stages and dried uniformly, were obtained from local shops in the Serra da Estrela region (Portugal) and kept in a cool, dry place until use. The crude extract was prepared as a source feedstock by grinding a sample of flower stylets $(5 \mathrm{~g})$ taken at random in $50 \mathrm{ml}$ of $0.1 \mathrm{M}$ citrate buffer $(\mathrm{pH}$ 5.4) and centrifuging at $6000 \mathrm{~g}$ for $5 \mathrm{~min}$ in a Sorvall Centrifuge RC5 (Wilmington DL, USA).

\subsection{Assay for microbial contamination}

Plate counts were performed on the crude plant material prepared in four different ways: whole flower stylets soaked in water, whole flower stylets macerated, whole flower stylets macerated with salt and whole flower stylets soaked in a salt solution. Plate count agar was used to enumerate total bacteria, yeast malt agar to enumerate moulds, caseinate agar to enumerate proteolytic bacteria and tributyrin agar to enumerate lipolytic bacteria. No Enterobacteriaceae, coliforms, yeasts on pseudomonads were found in these samples.

\subsection{Storage conditions}

Aqueous extracts that were not lyophilized before storage will hereafter be referred to as fresh extracts; part of these extracts was used promptly (0 days), another part was kept at $4^{\circ} \mathrm{C}$ for different storage times (1, 2 and 4 weeks) and the remaining part was lyophilized. For this latter portion, extracts were reconstituted either in water or in citrate buffer $(\mathrm{pH} 5.4)$ and used promptly (0 days), or kept at $4{ }^{\circ} \mathrm{C}$ for different storage times (1, 2 and 4 weeks). The length of the storage period was set as a compromise between feasible pilot storage in loco and feasible experimental storage in vitro. Experimental samples were run in duplicate.

\subsection{Assay for milk clotting activity}

Rennet clotting time was measured according to a standard method using low-heat bovine skim milk powder NILAC ${ }^{\mathrm{TM}}$ (NIZO, Ede, The Netherlands); the substrate was prepared by dissolving $12 \mathrm{~g}$ of milk powder in $100 \mathrm{ml}$ of $0.01 \mathrm{M} \mathrm{CaCl}_{2}(\mathrm{pH} 6.5)$ at $30^{\circ} \mathrm{C}$. Low 
heat-processed bovine skim milk was used as a standard and homogeneous substrate, even though the plant extracts tested do usually act upon whole ovine raw milk during cheesemaking. On the other hand, the degree of reconstitution was set according to the manufacturer's specifications of the process used during spray drying. The enzymatic assay was performed using $0.1 \mathrm{ml}$ of crude aqueous plant extract added to $2 \mathrm{ml}$ of reconstituted skim milk, and the clotting time was determined by visual inspection. One rennet unit (R.U.) was defined as the amount of crude enzyme extract needed to coagulate $10 \mathrm{ml}$ of reconstituted low-heat processed skim milk at $30^{\circ} \mathrm{C}$ in $100 \mathrm{~s}$ (FIL-IDF 157/1992). Determinations were duplicated, and the average of each pair of data was considered as a datum point.

\subsection{Assay for overall proteolytic activity}

Whole ovine and caprine Na-caseinate from Sigma (St. Louis MO, U.S.A.) were dissolved in $200 \mathrm{mM}$ phosphate buffer ( $\mathrm{pH}$ 6.5) to a final concentration of $100 \mathrm{~g} / 1$ and warmed up to $30^{\circ} \mathrm{C}$ in a thermostatted water bath. The reaction was started with addition of enzyme solution $(526 \mu \mathrm{l}$ of crude extract per $10 \mathrm{ml}$ of casein solution). Aliquots of $1 \mathrm{ml}$ were taken at $0,20,60,120$, $240,360,1440,1560,1680$ and $1800 \mathrm{~min}$ and added to 2 $\mathrm{ml}$ of $5 \%$ trichloroacetic acid (TCA) to quench the reaction. After resting for $10 \mathrm{~min}$, the samples were centrifuged at $12,000 \mathrm{~g}$ and absorbance of the clear supernatant was read at $280 \mathrm{~nm}$ in quartz cuvettes. Controls consisted of substrate solution without any added enzyme.

\subsection{Assay for specific proteolytic activity}

Whole ovine and caprine Na-caseinates were prepared, as described above, and the enzyme solution was added in a similar fashion. Aliquots of $750 \mu \mathrm{l}$ were taken at $6 \mathrm{~h}$, mixed with an equal volume of doubleconcentrated sample buffer (McSweeney, Olson, Fox, Healy \& Hojrup, 1993) and vortexed for $30 \mathrm{~s}$ prior to analysis by urea polyacrylamide gel electrophoresis (urea-PAGE). Urea-PAGE was performed using a Protean II XI vertical slab-gel unit (Bio-Rad Laboratories, Watford, UK) according to the method of Andrews (1983) (12.5\% T-acrylamide plus bisacrylamide, and $4 \%$ C-bisacrylamide referred to $\mathrm{T}, \mathrm{pH}$ 8.9) with modifications (Shalabi \& Fox, 1987); the gels were stained with Coomassie Blue G-250 (Bio-Rad, Richmond CA, USA) using the method of Blakesley and Boezi (1977). Quantification of intact $\beta$-casein (i.e. $\beta_{1^{-}}$and $\beta_{2}$-caseins) and $\alpha_{\mathrm{s}}$-casein (i.e. $\alpha_{\mathrm{s} 3^{-}}, \alpha_{\mathrm{s}^{-}}$and $\alpha_{\mathrm{s} 1^{-}}$-caseins) was done by densitometry using a GS-700 Imaging Densitometer (BioRad Laboratories, Hercules CA, USA). Determinations were duplicated, and the average of each pair of data was considered as a datum point.

\subsection{Statistical analyses}

The data pertaining to the global proteolytic activity were evaluated using two-way ANOVA (extract state and storage time) and using unpaired $t$-tests to compare means, both with the aid of the Statview ${ }^{\mathrm{TM}}$ package (Abacus concepts, Berkeley CA, USA). The data pertaining to the specific proteolytic activity were similarly analysed, using the same package, by a four-way ANOVA (extract state, storage time, caseinate type and hydrolysis time) coupled with Fisher's protected least significant difference tests for pairwise comparisons. The repeatabilities of the densitometric method were 94.4 and $94.2 \%$ for caprine and ovine urea-PAGE gels, respectively, whereas the standard errors in estimating the fractional degradation were 1.3 and $1.1 \%$ for $\beta$ - and $\alpha_{\mathrm{s}}$-casein, respectively.

\section{Results and discussion}

The clotting activity of the extracts stored under various conditions is plotted in Fig. 1. The clotting activity tended to decrease with storage time (Fig. 1), an observation expected in view of the spontaneous loss of the catalytically active conformation throughout the same time frame. Fresh extracts stored at $4{ }^{\circ} \mathrm{C}$ showed a $65 \%$ decrease in clotting activity over the 4 week period, having lost about $22 \%$ by week 2 of storage. Lyophilized extracts, reconstituted in water, showed a $34 \%$ decrease by 4 weeks, most of it occurring by week 2 of storage. Lyophilized extracts, reconstituted in citrate, showed a $38 \%$ decrease in this activity by 4 weeks, with $26 \%$ of such loss occurring by week 2 of storage. There is a higher loss in clotting activity of lyophilized extracts by week 1 of storage ( $44 \%$ when reconstituted in water and $61 \%$ when reconstituted in citrate buffer) than of fresh extracts ( $23 \%$ only); however, the same trend does not hold for the whole storage time (4 weeks), since the lyophilized extracts exihibited a lower loss in activity

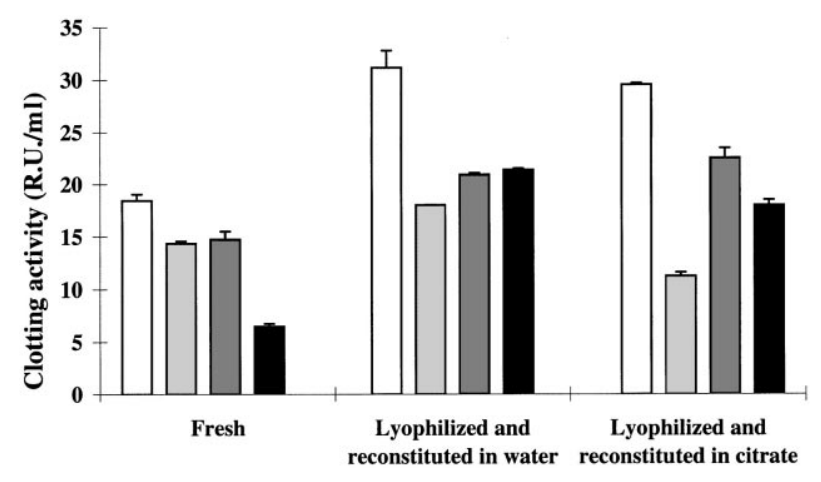

Fig 1. Clotting activity of fresh, lyophilized and reconstituted in plain water or in citrate buffer of extracts of Cynara cardunculus after storage at $4^{\circ} \mathrm{C}$ for 0 days $(\square), 1$ week ( $\square$ ), 2 weeks $(\square)$ and 4 weeks ( $\square$ ). 
(34\% for reconstitution in water and $38 \%$ for reconstitution in citrate) than fresh extracts $(65 \%$ decrease). Table 1 depicts the major ANOVA results for clotting activity with storage time (1, 2 and 4 weeks) and extract state (fresh, lyophilized and reconstituted in water, and lyophilized and reconstituted in citrate). The single factors (storage time and extract state) were highly significant $(P<0.0001)$ as well as their mutual interaction, hence suggesting that these two effects are not totally independent of each other; for fresh extracts the clotting time decreases with storage time whereas, for lyophilized extracts, it decreases after 1 week but then increases up to week 4 of storage (Fig. 1). This observation is probably a consequence of the change in conformation induced by the dramatic decrease in $a_{\mathrm{w}}$ brought about by lyophilization. When dehydrated, enzymes loose their ability to catalyze some reactions; a layer of bound water (water hydration shell) plays a key role in maintaining the structural integrity of the enzyme since it affects intramolecular salt bridges and hydrophobic interactions (Malcata, Garcia, Hill \& Amundson, 1992).

Table 1

ANOVA table for clotting activity (R.U./ml) as affected by storage time and extract state

\begin{tabular}{lccr}
\hline Treatment & Mean square & $F$-Value & $P$-Value \\
\hline Storage time & 405.67 & 10.90 & $<0.0001$ \\
Extract state & 473.27 & 12.71 & $<0.0001$ \\
Storage time $\times$ extract state & 127.25 & 3.42 & 0.0036 \\
Residual & 37.23 & & \\
\hline
\end{tabular}
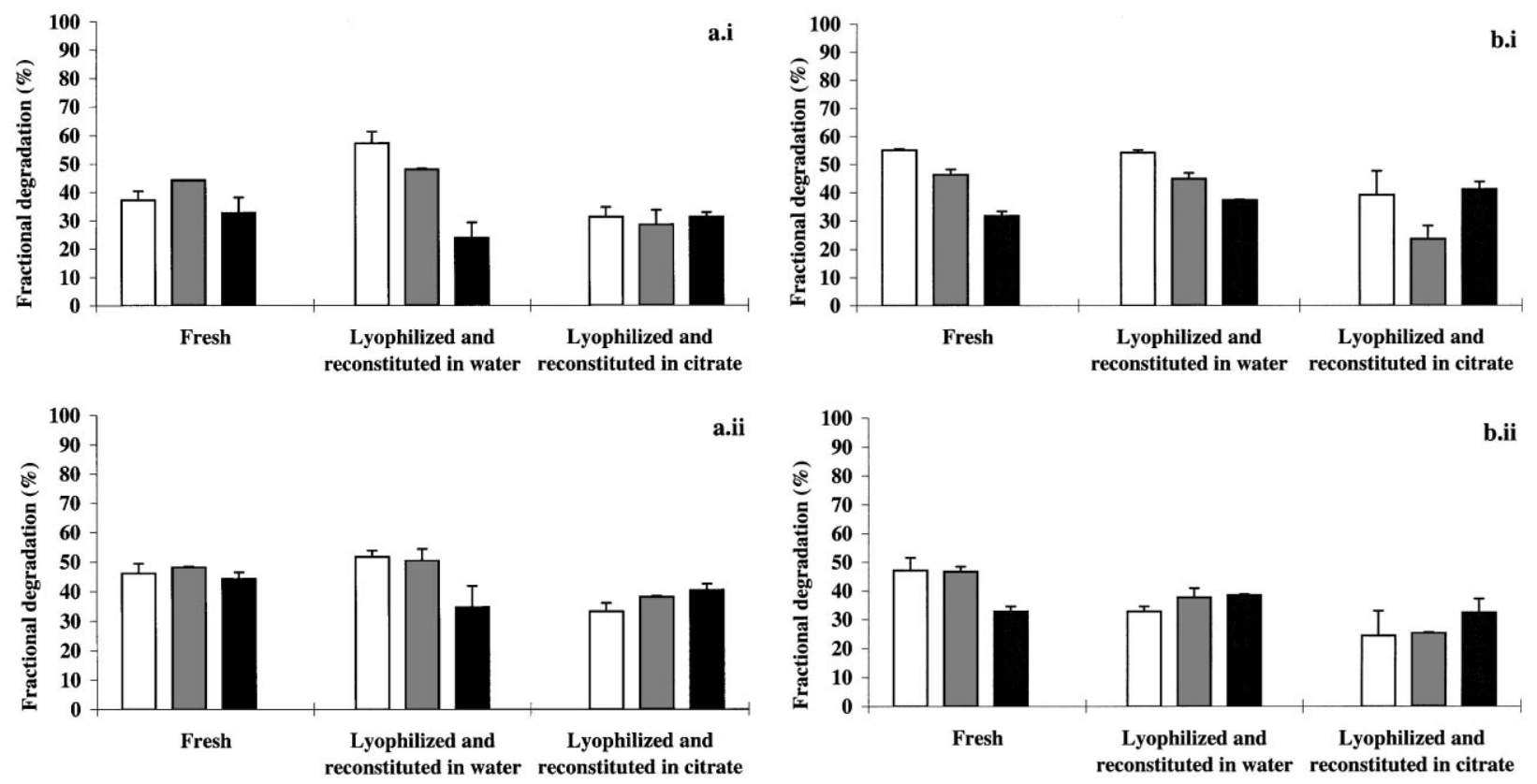

Fig 2. Fractional degradation of ovine (a) and caprine (b) caseinates in terms of $\beta$-casein (i) and $\alpha_{\mathrm{s}}$-casein (ii) after storage at $4^{\circ} \mathrm{C}$ for 0 days ( $\square$ ), 1 week $(\square)$ and 2 weeks
Furthermore, lyophilized extracts are less susceptible to enzymatic conformational changes during storage than fresh extracts, thus providing a rationale for the greater loss of clotting activity of fresh extracts over a longer storage period.

It may be argued that micro-organisms, growing in the extract solution upon storage, may have been implicated in some of our experimental observations; hence microbial plate counts were performed in the stored extracts. Results show that the dry flowers of $C$. cardunculus have $(0.75-5.0) \times 10^{3}$ colony forming units (cfu) of fungi per $\mathrm{g}$ and $(4.9-8.0) \times 10^{3} \mathrm{cfu} / \mathrm{g}$ of bacteria, with most isolates belonging to the genus Bacillus ( $B$. subtilis, B. licheniformis, B. pumilis and B. brevis). No significant differences were found upon salt addition or maceration. These numbers are far too low to account for increases in clotting activity via microbial production of organic acids in the time frame of coagulation. Extracts reconstituted in (unbuffered) water display, however, lower $\mathrm{pH}$ after storage than those reconstituted in citrate, and this may contribute to the higher clotting power of these extracts (lyophilized and reconstituted in water). Lyophilized extracts, reconstituted in citrate, show a significantly lower clotting activity than those reconstituted in water (and are not statistically different from fresh ones). These extracts, as opposed to those reconstituted in water, have citrate anions that can chelate calcium cations in solution, thus preventing or, at least, retarding coagulation.

Proteolytic breakdown of ovine $\beta$ and $\alpha_{\mathrm{s}}$-caseins (depicted in Fig. 2a) increased until week 1 of storage, 
and decreased between weeks 1 and 2 of storage when fresh extracts were employed (6.2 and $13.7 \%$ decrease by 2 weeks for $\beta$ - and $\alpha_{s}$-caseins, respectively); conversely, breakdown of $\alpha_{\mathrm{s}}$-casein increased but almost no change in ovine $\beta$-casein concentration with extract storage time was recorded when lyophilized extracts reconstituted in citrate were used (15.1 and $7.7 \%$ by week 2 , for $\beta$ - and $\alpha_{\mathrm{s}}$-caseins, respectively). On the other hand, proteolytic breakdown of these caseins decreased with increased storage time when lyophilized extracts reconstituted in water were used (31.9 and $33.2 \%$, for week 2 , for $\beta$ - and $\alpha_{\mathrm{s}}$-caseins, respectively). Caprine casein breakdown (Fig. 2b) also increased as the storage time of the extract increased when lyophilized extracts were tested (2.6 and $14.4 \%$, by week 2 , for $\beta$ - and $\alpha_{\mathrm{s}}-$ casein, respectively, for extracts reconstituted in water; 12.3 and $18.7 \%$, by week 2 , for extracts reconstituted in citrate). The capacity for proteolytic breakdown decreased with storage time for caprine caseins (33.8 and $9.4 \%$, by week 2 , for $\beta$ - and $\alpha_{\mathrm{s}}$-caseins, respectively) acted upon by fresh extracts. These trends were also somewhat confirmed by data for overall proteolytic activity, although not enough of these were available for a full statistical analysis. The percentage of degraded $\beta$ and $\alpha_{\mathrm{s}}$-caseins depicted in Fig. 2 shows that lyophilized extracts, right after reconstitution in water, degraded ovine and caprine caseins ( 62.0 and $55.1 \%$ of $\beta$-casein, and 57.5 and $34.5 \%$ of $\alpha_{\mathrm{s}}$-casein, respectively) to a greater extent than fresh extracts $(48.2$ and $68.9 \%$ of $\beta$ casein, and 50.7 and $50.1 \%$ of $\alpha_{\mathrm{s}}$-casein, respectively) or extracts lyophilized and reconstituted in citrate buffer (39.6 and $46.5 \%$ of $\beta$-casein, and 36.4 and $30.3 \%$ of $\alpha_{\mathrm{s}}$ casein, respectively), which were thus the least active.

When comparing degradation of $\beta$ - and $\alpha_{\mathrm{s}}$-caseins, one concludes that, in the initial periods of hydrolysis, the former substrate protein appears to be more resistant to degradation than the latter ( 6.0 vs. $21.4 \%$ for ovine, and 9.1 vs. $21.6 \%$ for caprine caseinates, respectively); however, as hydrolysis time elapses they are degraded to virtually the same extent in ovine caseinate $(51.8$ vs. $49.3 \%)$, whereas in caprine caseinate the reverse is actually observed ( $68.9 \%$ of $\beta$-casein degraded vs. $50.1 \%$ of $\alpha_{\mathrm{s}}$-casein). These observations are consistent with published data encompassing actual cheeses manufactured with extracts of $C$. cardunculus as rennet (Carretero et al., 1994; Mora \& Marcos, 1981; Sousa \& Malcata, 1996). The hydrophobic nature of $\beta$-casein probably allows binding to fat globules, thus making it more resistant to enzymatic attack, as also suggested elsewhere by Morgado (1991). This effect is more marked in ovine than caprine caseinate (only $48.2 \%$ of ovine, vs. $68.9 \%$ of caprine, $\beta$-casein is degraded by 24 h) because of the greater amount of fat present in ewe's milk $(6.5 \%)$ when compared to that in goat's milk (3.5\%) (Biss, 1991), even though ewe's milk has about twice the amount of casein as goat's milk.

Tables 2 and 3 tabulate the most important ANOVA results for fractional concentrations of intact $\beta$ - and $\alpha_{\mathrm{s}}$ casein, respectively. Inspection of these tables indicates that the caseinate type (i.e. ovine or caprine), state of the extract and storage time are statistically significant parameters $(P<0.05)$ for determination of fractional degradation of both $\beta$ - and $\alpha_{\mathrm{s}}$-caseins. However, the caseinate type is not a statistically significant parameter for degradation of $\beta$-casein when lyophilized extracts are used, but becomes highly significant when fresh extracts are employed (Table 4). This is also apparent by the non-significance of the interaction caseinate*hydrolysis time, meaning that caseinate type acts independently of hydrolysis time when lyophilized extracts bring about hydrolysis of $\beta$-casein. In the determination of the fractional concentration of $\alpha_{\mathrm{s}}$ casein (Table 5), the opposite is actually observed: when the hydrolysis is performed using lyophilized extracts,

Table 2

ANOVA table for fractional concentration of intact $\beta$-casein (\%) as affected by caseinate type, extract state, storage time and hydrolysis time

\begin{tabular}{|c|c|c|c|}
\hline Treatment & Mean square & $F$-Value & $P$-Value \\
\hline Caseinate type & 147.25 & 13.29 & 0.0004 \\
\hline Extract state & 1095.84 & 98.89 & $<0.00014$ \\
\hline Caseinate $\times$ extract state & 76.84 & 6.93 & 0.0015 \\
\hline Storage time & 718.68 & 64.85 & $<0.0001$ \\
\hline Caseinate $\times$ storage time & 351.94 & 31.76 & $<0.0001$ \\
\hline Extract state $\times$ storage time & 924.86 & 83.46 & $<0.0001$ \\
\hline Caseinate $\times$ extract state $\times$ storage time & 285.04 & 25.72 & $<0.0001$ \\
\hline Hydrolysis time & 12731.90 & 1148.90 & $<0.0001$ \\
\hline Caseinate $\times$ hydrolysis time & 50.45 & 4.55 & 0.0008 \\
\hline Extract state $\times$ hydrolysis time & 80.19 & 7.24 & $<0.0001$ \\
\hline Caseinate $\times$ extract state $\times$ hydrolysis time & 9.02 & 0.81 & 0.6162 \\
\hline Storage time $\times$ hydrolysis time & 80.93 & 7.30 & $<0.0001$ \\
\hline Caseinate $\times$ storage time $\times$ hydrolysis time & 25.13 & 2.27 & 0.0189 \\
\hline Extract state $\times$ storage time $\times$ hydrolysis time & 104.25 & 9.41 & $<0.0001$ \\
\hline Caseinate $\times$ extract state $\times$ storage time $\times$ hydrolysis time & 28.43 & 2.57 & 0.0010 \\
\hline Residual & 11.08 & & \\
\hline
\end{tabular}


Table 3

ANOVA table for fractional concentration of intact $\alpha_{\mathrm{s}}$-casein (\%) as affected by caseinate type, extract state, storage time and hydrolysis time

\begin{tabular}{|c|c|c|c|}
\hline Treatment & Mean square & $F$-Value & $P$-Value \\
\hline Caseinate type & 787.11 & 88.06 & $<0.0001$ \\
\hline Extract state & 1749.23 & 195.70 & $<0.0001$ \\
\hline Caseinate $\times$ extract state & 212.76 & 23.80 & $<0.0001$ \\
\hline Storage time & 50.10 & 5.61 & 0.0048 \\
\hline Caseinate $\times$ storage time & 272.75 & 30.52 & $<0.0001$ \\
\hline Extract state $\times$ storage time & 295.20 & 33.03 & $<0.0001$ \\
\hline Caseinate $\times$ extract state $\times$ storage time & 142.94 & 15.99 & $<0.0001$ \\
\hline Hydrolysis time & 9970.44 & 1115.40 & $<0.0001$ \\
\hline Caseinate $\times$ hydrolysis time & 82.51 & 9.23 & $<0.0001$ \\
\hline Extract state $\times$ hydrolysis time & 91.73 & 10.26 & $<0.0001$ \\
\hline Caseinate $\times$ extract state $\times$ hydrolysis time & 31.29 & 3.50 & 0.0005 \\
\hline Storage time $\times$ hydrolysis time & 25.93 & 2.90 & 0.0030 \\
\hline Caseinate $\times$ storage time $\times$ hydrolysis time & 13.79 & 1.54 & 0.1340 \\
\hline Extract state $\times$ storage time $\times$ hydrolysis time & 19.43 & 2.17 & 0.0059 \\
\hline Caseinate $\times$ extract state $\times$ storage time $\times$ hydrolysis time & 15.70 & 1.76 & 0.0350 \\
\hline Residual & 8.94 & & \\
\hline
\end{tabular}

Table 4

ANOVA table for fractional concentration of intact $\beta$-casein (\%) split by extract state

\begin{tabular}{|c|c|c|c|}
\hline & Mean square & $F$-Value & $P$-Value \\
\hline \multicolumn{4}{|l|}{ Fresh } \\
\hline Caseinate & 273.66 & 26.62 & $<0.0001$ \\
\hline Storage time & 469.95 & 45.72 & $<0.0001$ \\
\hline Caseinate $\times$ storage time & 349.77 & 34.03 & $<0.0001$ \\
\hline Hydrolysis time & 4614.51 & 448.89 & $<0.0001$ \\
\hline Caseinate $\times$ hydrolysis time & 27.48 & 2.67 & 0.0373 \\
\hline Storage time $\times$ hydrolysis time & 99.72 & 9.70 & $<0.0001$ \\
\hline Caseinate $\times$ storage time $\times$ hydrolysis time & 30.14 & 2.93 & 0.0086 \\
\hline Residual & 10.28 & & \\
\hline \multicolumn{4}{|l|}{ Lyophilized and reconstituted in water } \\
\hline Caseinate & 0.49 & 0.062 & 0.8043 \\
\hline Storage time & 1650.22 & 210.45 & $<0.0001$ \\
\hline Caseinate $\times$ storage time & 302.53 & 38.58 & $<0.0001$ \\
\hline Hydrolysis time & 5111.02 & 651.81 & $<0.0001$ \\
\hline Caseinate $\times$ hydrolysis time & 6.03 & 0.77 & 0.5780 \\
\hline Storage time $\times$ hydrolysis time & 123.03 & 15.69 & $<0.0001$ \\
\hline Caseinate $\times$ storage time $\times$ hydrolysis time & 24.91 & 3.18 & 0.0051 \\
\hline Residual & 7.84 & & \\
\hline \multicolumn{4}{|l|}{ Lyophilized and reconstituted in citrate } \\
\hline Caseinate & 26.77 & 1.77 & 0.1918 \\
\hline Storage time & 448.23 & 29.64 & $<0.0001$ \\
\hline Caseinate $\times$ storage time & 269.73 & 17.83 & $<0.0001$ \\
\hline Hydrolysis time & 3166.76 & 209.38 & $<0.0001$ \\
\hline Caseinate $\times$ hydrolysis time & 34.97 & 2.31 & 0.0640 \\
\hline Storage time $\times$ hydrolysis time & 66.69 & 4.41 & 0.0005 \\
\hline Caseinate $\times$ storage time $\times$ hydrolysis time & 26.93 & 1.78 & 0.1002 \\
\hline Residual & 15.12 & & \\
\hline
\end{tabular}

the caseinate type is highly significant $(P<0.0001)$ whereas it is not significant when using fresh extracts. The fact that the ternary interaction caseinate*storage time*hydrolysis time is not significant implies that these three factors play their roles independently with respect to $\alpha_{\mathrm{s}}$-casein degradation. The greater amount of solubilized plant material present in stored fresh extracts, than lyophilized ones, makes the first prone to acid production, hence promoting easier access to $\beta$-caseins as a result of dissolution of the fatty layer (by the acid) and also owing to their superficial location in the micelle. In this situation, the only significant factor determining $\beta$ casein degradation would be the amount of fat present in the caseinate, thus making the nature of milk a 
Table 5

ANOVA table for fractional concentration of intact $\alpha_{\mathrm{s}}$-casein (\%) split by extract state

\begin{tabular}{|c|c|c|c|}
\hline & Mean square & $F$-Value & $P$-Value \\
\hline \multicolumn{4}{|l|}{ Fresh } \\
\hline Caseinate & 0.41 & 0.10 & 0.7569 \\
\hline Storage time & 11.43 & 2.69 & 0.0818 \\
\hline Caseinate $\times$ storage time & 44.51 & 10.46 & 0.0003 \\
\hline Hydrolysis time & 4335.04 & 1018.90 & $<0.0001$ \\
\hline Caseinate $\times$ hydrolysis time & 6.47 & 1.52 & 0.2077 \\
\hline Storage time $\times$ hydrolysis time & 14.09 & 3.31 & 0.0039 \\
\hline Caseinate $\times$ storage time $\times$ hydrolysis time & 8.94 & 2.10 & 0.0504 \\
\hline Residual & 4.26 & & \\
\hline \multicolumn{4}{|l|}{ Lyophilized and reconstituted in water } \\
\hline Caseinate & 596.62 & 56.81 & $<0.0001$ \\
\hline Storage time & 182.87 & 17.41 & $<0.0001$ \\
\hline Caseinate $\times$ storage time & 476.09 & 45.34 & $<0.0001$ \\
\hline Hydrolysis time & 3529.77 & 336.12 & $<0.0001$ \\
\hline Caseinate $\times$ hydrolysis time & 72.94 & 6.95 & 0.0001 \\
\hline Storage time $\times$ hydrolysis time & 20.07 & 1.91 & 0.0760 \\
\hline Caseinate $\times$ storage time $\times$ hydrolysis time & 26.85 & 2.56 & 0.0190 \\
\hline Residual & 10.50 & & \\
\hline \multicolumn{4}{|l|}{ Lyophilized and reconstituted in citrate } \\
\hline Caseinate & 615.60 & 51.05 & $<0.0001$ \\
\hline Storage time & 446.21 & 37.00 & $<0.0001$ \\
\hline Caseinate $\times$ storage time & 38.03 & 3.15 & 0.0547 \\
\hline Hydrolysis time & 2289.09 & 189.83 & $<0.0001$ \\
\hline Caseinate $\times$ hydrolysis time & 65.66 & 5.45 & 0.0008 \\
\hline Storage time $\times$ hydrolysis time & 30.64 & 2.54 & 0.0197 \\
\hline Caseinate $\times$ storage time $\times$ hydrolysis time & 9.40 & 0.78 & 0.6475 \\
\hline Residual & 12.06 & & \\
\hline
\end{tabular}

Table 6

ANOVA table for fractional concentration of intact $\beta$-casein (\%) split by storage time

\begin{tabular}{|c|c|c|c|}
\hline & Mean square & $F$-Value & $P$-Value \\
\hline \multicolumn{4}{|l|}{0 days } \\
\hline Caseinate & 385.08 & 30.16 & $<0.0001$ \\
\hline Extract state & 1276.46 & 99.97 & $<0.0001$ \\
\hline Caseinate $\times$ extract state & 361.39 & 28.30 & $<0.0001$ \\
\hline Hydrolysis time & 5083.84 & 398.14 & $<0.0001$ \\
\hline Caseinate $\times$ hydrolysis time & 42.27 & 3.31 & 0.0146 \\
\hline Extract state $\times$ hydrolysis time & 136.11 & 10.66 & $<0.0001$ \\
\hline Caseinate $\times$ extract state $\times$ hydrolysis time & 29.29 & 2.29 & 0.0334 \\
\hline Residual & 12.77 & & \\
\hline \multicolumn{4}{|l|}{1 week of storage } \\
\hline Caseinate & 211.77 & 18.96 & 0.0001 \\
\hline Extract state & 1548.87 & 138.67 & $<0.0001$ \\
\hline Caseinate $\times$ extract state & 113.39 & 10.15 & 0.0003 \\
\hline Hydrolysis time & 4360.37 & 390.39 & $<0.0001$ \\
\hline Caseinate $\times$ hydrolysis time & 18.33 & 1.64 & 0.1741 \\
\hline Extract state $\times$ hydrolysis time & 121.75 & 10.90 & $<0.0001$ \\
\hline Caseinate $\times$ extract state $\times$ hydrolysis time & 17.99 & 1.61 & 0.1431 \\
\hline Residual & 11.17 & & \\
\hline \multicolumn{4}{|l|}{2 weeks of storage } \\
\hline Caseinate & 254.29 & 27.32 & $<0.0001$ \\
\hline Extract state & 120.22 & 12.92 & $<0.0001$ \\
\hline Caseinate $\times$ extract state & 172.15 & 18.50 & $<0.0001$ \\
\hline Hydrolysis time & 3449.55 & 370.63 & $<0.0001$ \\
\hline Caseinate $\times$ hydrolysis time & 40.11 & 4.31 & 0.0036 \\
\hline Extract state $\times$ hydrolysis time & 30.83 & 3.31 & 0.0039 \\
\hline Caseinate $\times$ extract state $\times$ hydrolysis time & 18.59 & 2.00 & 0.0631 \\
\hline Residual & 9.31 & & \\
\hline
\end{tabular}


Table 7

ANOVA table for fractional concentration of intact $\alpha_{\mathrm{s}}$-casein (\%) split by storage time

\begin{tabular}{|c|c|c|c|}
\hline & Mean square & $F$-Value & $P$-Value \\
\hline \multicolumn{4}{|l|}{0 days } \\
\hline Caseinate & 541.70 & 47.15 & $<0.0001$ \\
\hline Extract state & 1080.76 & 94.08 & $<0.0001$ \\
\hline Caseinate $\times$ extract state & 349.63 & 30.43 & $<0.0001$ \\
\hline Hydrolysis time & 3258.54 & 283.64 & $<0.0001$ \\
\hline Caseinate $\times$ hydrolysis time & 48.55 & 4.23 & 0.0040 \\
\hline Extract state $\times$ hydrolysis time & 53.60 & 4.67 & 0.0003 \\
\hline Caseinate $\times$ extract state $\times$ hydrolysis time & 33.42 & 2.91 & 0.0090 \\
\hline Residual & 11.49 & & \\
\hline \multicolumn{4}{|l|}{1 week of storage } \\
\hline Caseinate & 783.75 & 163.64 & $<0.0001$ \\
\hline Extract state & 1007.44 & 210.34 & $<0.0001$ \\
\hline Caseinate $\times$ extract state & 60.33 & 12.60 & $<0.0001$ \\
\hline Hydrolysis time & 3527.69 & 736.53 & $<0.0001$ \\
\hline Caseinate $\times$ hydrolysis time & 44.51 & 9.29 & $<0.0001$ \\
\hline Extract state $\times$ hydrolysis time & 53.53 & 11.18 & $<0.0001$ \\
\hline Caseinate $\times$ extract state $\times$ hydrolysis time & 23.12 & 4.83 & 0.0002 \\
\hline Residual & 4.79 & & \\
\hline \multicolumn{4}{|l|}{2 weeks of storage } \\
\hline Caseinate & 7.16 & 0.68 & 0.4151 \\
\hline Extract state & 251.43 & 23.86 & $<0.0001$ \\
\hline Caseinate $\times$ extract state & 88.67 & 8.42 & 0.0010 \\
\hline Hydrolysis time & 3236.07 & 307.12 & $<0.0001$ \\
\hline Caseinate $\times$ hydrolysis time & 17.03 & 1.62 & 0.1807 \\
\hline Extract state $\times$ hydrolysis time & 23.46 & 2.23 & 0.0386 \\
\hline Caseinate $\times$ extract state $\times$ hydrolysis time & 6.15 & 0.58 & 0.8163 \\
\hline Residual & 10.54 & & \\
\hline
\end{tabular}

Table 8

ANOVA table for fractional concentration of intact $\beta$-casein (\%) split by caseinate type

\begin{tabular}{lrr}
\hline & Mean square & $F$-Value \\
\hline Ovine caseinate & & $P$-Value \\
Extract state & 597.66 & 37.86 \\
Storage time & 478.54 & 54.49 \\
Extract state $\times$ storage time & 688.84 & 451.25 \\
Hydrolysis time & 5704.44 & 4.32 \\
Extract state $\times$ hydrolysis time & 54.62 & 3.61 \\
Storage time $\times$ hydrolysis time & 45.61 & 3.44 \\
Storage time $\times$ extract state $\times$ hydrolysis time & 43.53 & 0.0001 \\
Residual & 12.64 & 0.0001 \\
Caprine caseinate & & 0.0002 \\
Extract state & 575.01 & $<2$ \\
Storage time & 592.09 & 62.18 \\
Extract state $\times$ storage time & 521.06 & 54.72 \\
Hydrolysis time & 7077.91 & 743.30 \\
Extract state $\times$ hydrolysis time & 34.59 & 3.63 \\
Storage time $\times$ hydrolysis time & 60.45 & 6.35 \\
Storage time $\times$ extract state $\times$ hydrolysis time & 89.15 & $<.36$ \\
Residual & 9.52 & $<0.0001$ \\
\hline
\end{tabular}

significant effect. When using lyophilized extracts, the same is observed but with respect to $\alpha_{\mathrm{s}}$-casein degradation. The rigid structure of these extracts and the small amount of plant material in solution, associated with the internal location of these caseins that makes them less labile to enzymatic attack, is likely responsible for the relevance of the caseinate type. Inspection of the ANOVA tables for fractional concentrations of $\beta$ - and $\alpha_{\mathrm{s}}$-caseins after splitting by storage time (Tables 6 and 7 , respectively) indicates that the caseinate type is not significant towards $\alpha_{\mathrm{s}}$-casein degradation by week 2 of storage; the ANOVA split by caseinate type for $\beta$ - and 
Table 9

ANOVA table for fractional concentration of intact $\alpha_{\mathrm{s}}$-casein (\%) split by caseinate type

\begin{tabular}{|c|c|c|c|}
\hline & Mean square & $F$-Value & $P$-Value \\
\hline \multicolumn{4}{|l|}{ Ovine caseinate } \\
\hline Extract state & 477.79 & 62.19 & $<0.0001$ \\
\hline Storage time & 124.67 & 16.23 & $<0.0001$ \\
\hline Extract state $\times$ storage time & 314.47 & 40.93 & $<0.0001$ \\
\hline Hydrolysis time & 5881.71 & 765.53 & $<0.0001$ \\
\hline Extract state $\times$ hydrolysis time & 31.63 & 4.12 & 0.0003 \\
\hline Storage time $\times$ hydrolysis time & 23.41 & 3.05 & 0.0039 \\
\hline Storage time $\times$ extract state $\times$ hydrolysis time & 17.65 & 2.30 & 0.0081 \\
\hline Residual & 7.68 & & \\
\hline \multicolumn{4}{|l|}{ Caprine caseinate } \\
\hline Extract state & 1484.20 & 145.60 & $<0.0001$ \\
\hline Storage time & 198.18 & 19.44 & $<0.0001$ \\
\hline Extract state $\times$ storage time & 123.67 & 12.13 & $<0.0001$ \\
\hline Hydrolysis time & 4171.23 & 409.21 & $<0.0001$ \\
\hline Extract state $\times$ hydrolysis time & 91.38 & 8.97 & $<0.0001$ \\
\hline Storage time $\times$ hydrolysis time & 16.31 & 1.60 & 0.1316 \\
\hline Storage time $\times$ extract state $\times$ hydrolysis time & 17.49 & 1.72 & 0.0596 \\
\hline Residual & 10.19 & & \\
\hline
\end{tabular}

$\alpha_{\mathrm{s}}$-degradation (Tables 8 and 9 , respectively) indicates that there are no significant differences between the performance of fresh extracts and lyophilized ones reconstituted in water with respect to degradation of caprine $\beta$-casein and ovine $\alpha_{\mathrm{s}}$-casein, between storage of the extracts for week 1 and week 2 for degradation of caprine $\beta$-casein, and between storage for day 0 and week 1 for degradation of ovine $\beta$-casein and caprine $\alpha_{\mathrm{s}}$ casein; the ANOVA split by hydrolysis time was also performed (data not shown), and its inspection revealed that the time of storage is only significant from $2 \mathrm{~h}$ of hydrolysis onwards, while the state of the extract is significant at all hydrolysis times; in the degradation of $\beta$-casein, the caseinate source is not an important factor up to $4 \mathrm{~h}$ of hydrolysis, but it becomes significant thereafter $(P<0.05)$; finally, in the degradation of $\alpha_{\mathrm{s}}$ casein, the caseinate source is a significant factor by as early as $2 \mathrm{~h}$ of hydrolysis and the state of the extract is always significant, whereas the time of storage is only significant for $2 \mathrm{~h}$ of hydrolysis (thus suggesting different specificities towards $\beta$ - and $\alpha_{\mathrm{s}}$-caseins). The estimated interaction between the type of caseinate and the mode of preparation of the extract supports this statement because the interaction at any given hydrolysis time is never significant for $\beta$-casein (i.e. degradation of ovine and caprine $\beta$-caseins is not dependent on the extract used) but is always significant for $\alpha_{\mathrm{s}}$-casein; possibly the three-dimensional structure and location of $\alpha_{\mathrm{s}}$-casein within the micelle hinders enzymatic attack.

Lyophilized extracts reconstituted in water and stored at $4{ }^{\circ} \mathrm{C}$ showed higher clotting activity and greater proteolytic activity than fresh or lyophilized extracts reconstituted in citrate. Fresh extracts have lower clotting power than lyophilized extracts but not statistically different from that of lyophilized extracts reconstituted in citrate buffer. With respect to casein degradation ( $\beta$ and $\alpha_{\mathrm{s}}$-casein), lyophilized extracts reconstituted in citrate were again statistically different from either fresh extracts or lyophilized extracts reconstituted in water. These extracts degraded both caseins to a smaller extent than fresh extracts or lyophilized extracts reconstituted in water. The chelating effect of citrate ions (by tying up colloidal calcium), associated with the lyophilization effect (which provides a more stable structure), may be the underlying cause of this low proteolytic activity. The lyophilization process seemed to retard loss of clotting activity throughout storage and to avoid proteolytic breakdown of the milk caseins when the extracts were reconstituted in citrate buffer.

\section{Conclusions}

Lyophilization retards loss of clotting activity throughout storage, probably by providing a more stable conformation of the enzyme. This process, coupled with reconstitution in citrate buffer, significantly decreases ovine and caprine $\left(\beta-\right.$ and $\alpha_{\mathrm{s}}$ ) casein breakdown. Storage at $4^{\circ} \mathrm{C}$ decreases clotting power significantly, with a greater loss for fresh extracts than for lyophilized ones. Ovine casein breakdown increases with storage time in fresh and lyophilized extracts reconstituted with citrate, and decreases when extracts are reconstituted with water. Caprine casein breakdown increases with storage when lyophilized extracts are used, but decreases in the case of fresh extracts. However, lyophilized extracts reconstituted in citrate are the least proteolytic.

Therefore, use of lyophilized extracts from flowers of C. cardunculus reconstituted with citrate buffer is sug- 
gested as a good alternative to fresh extracts (that have been employed for years in the manufacture of traditional cheeses from ovine and caprine milks in Portugal), to the extent that in vitro conclusions using a model system (caseinate) can be extrapolated to actual cheeses manufactured from whole milk of the same source.

\section{References}

Andrews, A. T. (1983). Proteinases in normal bovine milk and their action on caseins. Journal of Dairy Research, 50, 45-55.

Biss, K. (1991). Sheep and goat cheese. Journal of the Society of Dairy Technology, 44, 104-106.

Blakesley, R. W., \& Boezi, J. A. (1987). A new staining technique for proteins in polyacrylamide gels using Coomassie Brillant Blue G250. Analytical Biochemistry, 82, 55-581.

Boulanger, A., Grosclaude, F., \& Mahé, M. F. (1984). Polymorphism of goat $\alpha_{\mathrm{s}^{-}}$and $\alpha_{\mathrm{s} 2}$-caseins. Genetic Selection and Evolution, 16, $157-176$.

Cabezas, L., Esteban, M. A., \& Marcos, A. (1981). Agar gel diffusion of Cynara humilis (L.) proteinases and other enzymes. Alimentaria, 128, 17-22.

Campos, R., Guerra, R., Aguiar, M., Ventura, O., \& Camacho, L. (1990). Chemical characterization of proteases extracted from wild thistle (Cynara cardunculus). Food Chemistry, 35, 89-97.

Carretero, C., Trujillo, A. J., Mor-Mur, M., Pla, R., \& Guamis, B. (1994). Electrophoretic study of casein breakdown during ripening of goat's milk cheese. Journal of Agricultural and Food Chemistry, 42, 1546-1550.

Cattaneo, T. M. P., Nigro, F., Messina, G., \& Giangiacomo, R. (1994). Effect of an enzymatic complex from pineapple pulp on the primary clotting phase. Milchwissenschaft, 49, 269-272.

Cordeiro, M. C., Jakob, E., Puhan, Z., Pais, M. S., \& Brodelius, P. E. (1992). Milk clotting and proteolytic activities of purified cynarases from Cynara cardunculus - a comparison to chymosin. Milchwissenchaft, 47, 683-700.

Domingos, A., Xue, Z. T., Guruprasad, K., Clemente, A., Blundell, T., Pais, M. S., \& Brodelius, P. (1996). An aspartic proteinase from flowers of Centaurea calcitrapa: purification, characterization, molecular cloning and modelling of its three-dimensional structure. Poster presented at the VIIth International Aspartic Proteinase Conference, Banff, Canada, p. 7-6.

El-Salam, M. H. A., El-Dein, H. F., Mahfouz, M. B., Sharaf, O. M., \& Hefnawy, S. A. (1989). Activity and microbiological quality of rennet extracts from fresh vells as affected by the used preservative and storage period. Egyptian Journal of Dairy Science, 17, 75-85.

Faro, C. (1991) Purificação e caracterização físico-química da protease de Cynara cardunculus (L.). PhD thesis, Universidade de Coimbra, Portugal.

Green, M. L. (1972). Assessment of swine, bovine and chicken pepsin as rennet substitutes for cheddar cheese-making. Journal of Dairy Research, 39, 261-265.

Gupta, C. B., \& Eskin, N. A. M. (1977). Potential use of vegetable rennet in the production of cheese. Food Technology, 31, 62-64.

Heimgartner, U., Pietrzak, M., Geertsen, R., Brodelius, P., Silva Figueiredo, A. C., \& Pais, M. S. S. (1990). Purification and partial characterization of milk clotting proteases from flowers of Cynara cardunculus. Phytochemistry, 29, 1405-1410.

International IDF Standard (1992). Bovine rennets; Determination. Federation, 157, 1-4.

Ibiama, E., \& Griffiths, M. W. (1987). Studies on a milk-coagulating enzyme, 'Calotropain', obtained from sodom apple (Calotropis procera). Journal of Food and Agriculture, 1, 157-162.

Macedo, A., Malcata, F. X., \& Oliveira, J. C. (1993). The technology, chemistry and microbiology of Serra cheese: a review. Journal of Dairy Science, 76, 1725-1739.

Malcata, F. X., Reyes, H. R., Garcia, H. S., Hill, C. G., \& Amundson, C. H. (1992). Kinetics and mechanisms of reactions catalysed by immobilized lipases. Enzyme Microbial Technology, 14, 426-446.

McSweeney, P. L. H., Olson, N. F., Fox, P. F., Healy, A., \& Hojrup, P. (1993). Proteolytic specificity of chymosin on bovine $\alpha_{\mathrm{s} 1}$-casein. Journal of Dairy Research, 60, 401-412.

Mora, M. T., \& Marcos, A. (1981). Proteolysis del cheso Manchego: caseinas y productos de degradacion insolubles. Arch. Zootec, 30, 1-17.

Morgado, J. M. (1991). Estudo comparativo da acção de três proteases coagulantes do leite sobre as caseínas isoladas e em micelas. Ms. thesis. Universidade de Coimbra, Portugal.

Padmanabhan, S., Chitre, A., \& Shastri, N. V. (1993). Milk clotting protease isolated from Dieffenbachia maculata. Die Nahrung, 37, 99-101.

Richardson, B. C., \& Creamer, L. K. (1975). Comparative micelle structure IV. The similarity between caprine $\alpha_{\mathrm{s}}$-casein and bovine $\alpha_{\mathrm{s} 3}$-casein. Biochimica et Biophysica Acta, 393, 37-47.

Richardson, B. C., \& Creamer, L. K. (1976). Comparative micelle structure V. The characterization and isolation of major ovine caseins. New Zealand Journal of Dairy Science and Technology, 11, 46-53.

Shalabi, S. I., \& Fox, P. F. (1987). Electrophoretic analysis of cheese: comparison of methods. Irish Journal of Food Science and Technology, 11, 135-151.

Singh, J., Chandler, H., Bhalerao, V. R., \& Dastur, N. N. (1973). Studies on vegetable rennet from Withania coagulans. Journal of Food Science and Technology, 10, 16-19.

Sousa, M. J., \& Malcata, F. X. (1996). Comparison of plant and animal rennets in terms of microbiological, chemical and proteolysis characteristics of ovine cheese. Journal of Agricultural and Food Chemistry, 45, 74-81.

Vieira de Sá, F., \& Barbosa, M. (1972). Cheese-making with a vegetable rennet from cardo (Cynara cardunculus). Journal of the International Dairy Federation, 39, 335-343. 